\title{
Antimicrobial Resistant Determination and Prokaryotic Expression of smpA Gene of Acinetobacter baumannii Isolated from Admitted Patients
}

\author{
Hossein Ansari, ${ }^{1,2}$ Abbas Doosti, ${ }^{3,}{ }^{*}$ Mohammad Kargar, ${ }^{4}$ Mahdi Bijanzadeh, ${ }^{5}$ and Mojtaba Jafarinya ${ }^{2}$ \\ ${ }^{1}$ Department of Genetic, Science and Research Branch, Islamic Azad University, Shiraz, IR Iran \\ ${ }^{2}$ Department of Genetic, Marvdasht branch, Islamic Azad University, Marvdasht, IR Iran \\ ${ }^{3}$ Department of Genetic, University of Michigan Hospital and Health Centers, Michigan, USA \\ ${ }^{4}$ Department of Microbiology, Jahrom Branch, Islamic Azad University, Jahrom, IR Iran \\ ${ }^{5}$ Department of Medical Genetic, Ahvaz Jundishapur University of Medical Sciences, Ahvaz, IR Iran \\ "Corresponding author: Abbas Doosti, University of Michigan Hospital and Health Centers, Michigan, USA. Tel: +1-2814109545, E-mail: abbasdoosti@yahoo.com
}

Received 2017 February 28; Revised 2017 August 06; Accepted 2017 August 16.

\begin{abstract}
Background: Acinetobacter baumannii is a leading cause of worldwide nosocomial infections. As many infections are caused by multidrug-resistant strains, the antibiotic-therapy of them has become greatly difficult.

Objectives: The present study was aimed to evaluate the antimicrobial susceptibility of A. baumannii as well as cloning and expression of A. baumannii-smpA gene isolated from infectious patients.

Methods: Sixty-seven samples were collected from different clinical infections wards especially intensive-care units (ICU). The $A$. baumannii was identified according to bacteriological standard method. The antibiotic resistance patterns of the isolates were analyzed by the disk diffusion method. The smpA was amplified by Polymerase chain reaction (PCR) following cloning and sub-cloning in T-vector and expression vector, respectively. Colony-PCR, double-digestion and DNA sequencing confirmed that smpA was cloned into the vectors. The expression of rSmpA in IPTG-induced E. coli-DE3 was examined by Sodium dodecyl sulfate polyacrylamide gel electrophoresis (SDS-PAGE).

Results: Thirty out of 67 isolates (44.78\%) were positive for A. baumannii among which, more than $83 \%$ were resistance to all generation of Cephalosporins and the least resistance (10\%) was observed for Colistin. The smpA-amplicon was $417 \mathrm{bp}$. Colony-PCR, double-digestion and sequencing showed that the target gene was inserted into the pTZ57RT and pET32a (+), successfully. Obtaining of a $\sim 15$ KDa band in SDS-PAGE showed the recombinant pET32a/smpA was highly expressed.

Conclusions: These results indicated that high resistance to antibiotics among isolates and high conserved of smpA gene at sequence level among A. baumannii strains, therefore it can be used as an antigenic target for generation vaccine against multi drug resistant (MDR) A. baumannii infections.
\end{abstract}

Keywords: Antibiotic Resistance, Intensive Care Unit, Prokaryotic Expression Vector, Small Outer-Membrane Lipoprotein A, Vaccine, Acinetobacter baumannii

\section{Background}

Acinetobacter baumannii is a Gram-negative bacillus, pleomorphic but almost rod-shaped or coccobacillus, oxidase negative, catalase positive, non-motile, non-spore former bacterium and obligate aerobic $(1,2)$. This organism can be found widespread in nature and have been separated from water, soil and various samples of animal and human. Acinetobacter baumannii is able to adhere to the biotic and abiotic surfaces like the hospital equipment's and can survive on these dry surfaces for long periods of time (2-5). The above mentioned properties of these species and the emerging antibiotic resistance for A. baumannii, could be related to biofilm formation. Outer membrane proteins (OMPs) are the plentiful surface proteins of this organism and have been exhibited to be necessary for its adherence (3-5).

Acinetobacter species (especially A. baumannii) are resistant to the most of the achievable antimicrobial agents and clinically useful antibiotics such as: aminoglycosides, fluoroquinolones, carbapenems and $\beta$-lactams $(1,2,6,7)$. Strains of Acinetobacter species. specifically Multi-drug and pan-drug resistant $A$. baumannii have been greatly separated from compromised patients with an underlying infectious including pneumonia (both hospital and community acquired), wound sepsis, urinary tract infections, septicemia and meningitis (6, 8-11).

The treatment of these infections has become greatly difficult due to the multi-drug, pan-drug and extreme-drug resistant (MDR, PDR and EDR) A. baumannii, an important 
cause of nosocomial infections (6, 9-15). The most important way for restriction of infectious diseases is vaccination. Vaccines have nearly or completely, eradicated both bacterial and viral infections, for examples, approximately complete eradication of poliomyelitis, elimination of smallpox and a diminution of more than $95 \%$ in the prevalence of diseases such as measles, pertussis, diphtheria, mumps, rubella and tetanus (16).

The second generation of vaccine can give some advantages such as complete prevention of infection and stability. In case of recombinant vaccines, gene(s) encoding antigenic proteins of a pathogen are inserted into the plasmid resulted in synthesis of these proteins inside the prokaryotic cells. After purification and injection of these proteins, followed by antigen presentation, an immune response can be induced (17). Therefore, we selected the high prevalence and conserved small outer-membrane lipoprotein A (SmpA) and used the pET expression system for gene expression and production of recombinant proteins in prokaryotic hosts (17).

It is necessary to mention that small outer-membrane lipoprotein A (SmpA, OmlA family) is associated with the YaeT complex. The YaeT complex is essential for the erection of OMPs into the outer membrane, and two of its members, YfiO and YaeT are necessary in Gram-negative bacterial in a way that deficiency of them may be incapable to comfortably assemble OMPs in the outer membrane. Strains with SmpA deficiency may present the heightened sensitivity to detergents and toxic miscellaneous toxic small molecules such as SDS, Deoxycholate, Tween-20, TritonX100, EDTA, Antibiotics, $\mathrm{H}_{2} \mathrm{O}_{2}$ and Paraquat $(18,19)$.

\section{Objectives}

The present study was aimed to perform the elementary steps in generation vaccine against MDR A. baumannii infections, including strains isolation from clinical samples in different wards, identification and evaluation of their antibiotic resistance patterns, cloning and expression of antigenic smpA gene A. baumannii in pET32(a). So, the results of present study will supply further experimental foundation for the development of A. baumannii vaccines.

\section{Methods}

\subsection{Bacterial Isolates}

Sixty-seven samples were collected from the different clinical infectious cases including wound pus (18 isolates), urinary tract infections (10 isolates), septicemia (14 blood isolates) and pneumonia (25 sputum isolates) in different wards of Kashani and Imam Ali hospitals Shahrekord, southwest Iran during September 2015 to April 2016. The majority of cases were hospitalized in the ICU. All the samples were cultured on solid media (McConkey; Merck, Germany) and blood agar. Afterwards A. baumannii were diagnosed with biochemical and bacteriological standard tests. The isolates were stored at $-70^{\circ} \mathrm{C}$ in Trypticase Soy Broth (Merck, Germany) supplemented with 15\% glycerol before being tested.

\subsection{Antimicrobial Susceptibility Testing}

The susceptibility of all antimicrobial agents' isolates was determined by disk diffusion method, as recommended by the CLSI. The following antimicrobial agents (listed in Table 1) were provided by their manufacturers (MAST, Co, UK and Liofilichem, Co, Italy) for use in this study. The isolates were grown overnight on TSA supplemented with $5 \%$ sheep blood at $37^{\circ} \mathrm{C}$. Acinetobacterbaumannii ATCC19606 and E. coli ATTC25922 were taken from the IBRC, Iran, Karaj which was used for quality control purposes in antibacterial susceptibility determination.

\subsection{DNA Extraction}

Genomic DNA of A. baumannii strain was extracted by DNA Mini Kit (Qiagen, Germany) according to the manufacturer's guideline. Quality and quantity of the extracted genomic DNA were assessed by $1 \%$ agarose gel electrophoresis and the absorbance of purified DNA was measured at a wavelength of $260 / 280 \mathrm{~nm}$ by NanoDropND1000 spectrophotometer.

\subsection{Gene Amplification}

Gene encoding of the SmpA, nearly length in $417 \mathrm{bp}$ was amplified by PCR method. Primers were designed with Gene Runner software according to the published sequence for smpA gene of the A. baumannii NCBI GenBank (Accession number: CP003967), and their exactitude was confirmed by BLAST (http//ncbi,nlm,nih.gov/BLAST). The sequences of these primers include smpA-Forward: 5'-ATAGTCGACATGCAAAAACTCGTGCTGAC-3' and smpAReverse: 5'-TCTGCGGCCGCTTATAGTGGTGGGGCAGTTA-3'. For subsequent cloning of the PCR-product fragments, SalI and NotI restriction sites were joined to the 5' end of these primers, respectively. The amplification was done using Thermal Cycler (Eppendrof, Germany), in a final reaction volume of $30 \mu \mathrm{L}$. The PCR mixture consisted of $4 \mu \mathrm{L}$ of $10 \mathrm{X}$ PCR buffer, $2 \mu \mathrm{L} \mathrm{MgCl}_{2}, 2 \mu \mathrm{L}$ dNTPs (10 mM), $1.5 \mu \mathrm{L}$ of each primer, $2 \mu \mathrm{L}$ of DNA sample and $1 \mathrm{U}$ of Taq DNA polymerase (Fermentas, Germany) and final volume was adjusted with 
Table 1. In Vitro Susceptibilities for 30 Clinical Isolates of A. baumannii from Patients, in Different Wards of Imam Ali and Kashani Hospitals Determined by Disk Diffusion Method $^{\mathrm{a}}$

\begin{tabular}{|c|c|c|c|}
\hline Antibiotic & $S$ & I & $\mathbf{R}$ \\
\hline \multicolumn{4}{|l|}{ Penicillin } \\
\hline Amoxicillin & $0(0)$ & $0(0)$ & $30(100)$ \\
\hline \multicolumn{4}{|l|}{ Cephalosporin } \\
\hline Cefoxitin & $2(6.67)$ & $3(10)$ & $25(83.33)$ \\
\hline Cefixime & $0(0)$ & $0(0)$ & $30(100)$ \\
\hline Cefotaxime & $0(0)$ & $0(0)$ & $30(100)$ \\
\hline Cefoprazone & $0(0)$ & $0(0)$ & $30(100)$ \\
\hline \multicolumn{4}{|l|}{ Carbapenms } \\
\hline Imipenem & $10(33.33)$ & $3(10)$ & $17(56.67)$ \\
\hline Doripenem & $4(13.33)$ & $10(33.33)$ & $16(53.34)$ \\
\hline \multicolumn{4}{|l|}{ Macrolide } \\
\hline Erythromycin & $0(0)$ & $0(0)$ & $30(100)$ \\
\hline \multicolumn{4}{|l|}{ Lincosamide } \\
\hline Clindamycin & $10(33.33)$ & $12(40)$ & $8(26.67)$ \\
\hline \multicolumn{4}{|l|}{ Quinolones } \\
\hline Nalidixic acid & $1(3.33)$ & $5(16.67)$ & $24(80)$ \\
\hline Ofloxacin & $1(3.33)$ & $3(10)$ & $26(86.67)$ \\
\hline Levofloxacin & $6(20)$ & $4(13.33)$ & $20(66.67)$ \\
\hline \multicolumn{4}{|l|}{ Sulfonamides } \\
\hline Sulfamethoxazole & $5(16.67)$ & $3(10)$ & $22(73.33)$ \\
\hline \multicolumn{4}{|l|}{ Tetracycline } \\
\hline Minocycline & $14(46.67)$ & $10(33.33)$ & $6(20)$ \\
\hline \multicolumn{4}{|l|}{ Glycylcycline } \\
\hline Tigecycline & $5(16.67)$ & $7(23.33)$ & $18(60)$ \\
\hline \multicolumn{4}{|l|}{ Polypeptides } \\
\hline Colistin & $23(76.67)$ & $4(13.33)$ & $3(10)$ \\
\hline Polymyxin B & $17(56.67)$ & $8(26.67)$ & $5(16.67)$ \\
\hline
\end{tabular}

Abbreviations: I, Intermediate; R, Resistance; S, Susceptible.

${ }^{a}$ Values are expressed as No.(\%).

nuclease-free water. The following conditions were applied: initial denaturation at $95^{\circ} \mathrm{C}$ for 5 minutes, followed by 32 cycles; denaturation at $94^{\circ} \mathrm{C}$ for 1 minute, annealing at $61^{\circ} \mathrm{C}$ for 1 minute, elongation at $72^{\circ} \mathrm{C}$ for 45 seconds. The program was ensued by final elongation at $72^{\circ} \mathrm{C}$ for 5 minutes and amplified sample was held at $15^{\circ} \mathrm{C}$.

\subsection{Valuation of Amplification Products and T/A Cloning}

The PCR products were analyzed on 1.5\% agarose gel electrophoresis, and photographed under UVIdoc gel documentation systems (Uvitec, UK). The amplification prod- uct was purified from the gel using gel extraction kit (Bioneer Co., Korea) according to the manufacturer protocol and cloned in pTZ57RTvector (Thermo Scientific, Lithuania). The engineered vector was transformed into the Escherichia coli Nova Blue competent cells by calcium chloride solution method using heat shock (at $42^{\circ} \mathrm{C}$ for 2 minutes and $4^{\circ} \mathrm{C}$ for 10 minutes). Transformed cells were cultured in LB agar (Merck, Germany) containing Ampicillin antibiotic $(100 \mu \mathrm{g} / \mathrm{mL})$, IPTG $(0.1 \mathrm{M})$ and Xgal $(20 \mathrm{mg} / \mathrm{mL})$ for screening of recombinant vectors at $37^{\circ} \mathrm{C}$ overnight. The recombinant vectors were extracted from bacterial cells using plasmid mini extraction kit (Bioneer, Korea) using manufacturer's guideline. PCR and double digestion with the Sall and NotI (buffer for double digestion: orange/1X) analysis were carried out for confirmation of cloning.

\subsection{Sub-Cloning of smpA Gene Into pET32a (+)}

After double digestion pTZ57R/T-smpA and pET32a (+) with the same restriction enzymes, smpA and linearized pET32a(+) were reclaimed by gel extract kit (Bioneer, Korea), and ligated by using T4 DNA ligase at $4^{\circ} \mathrm{C}$ overnight and generate the engineered pET32a-smpA according to directional cloning method. The $E$.coli Nova Blue was used for transformation by calcium chloride method and cultured in LB agar media containing $100 \mu \mathrm{g} / \mathrm{mL}$ ampicillin. This construct was confirmed by PCR, double digestion and sequencing.

\subsection{Gene Expression}

The pET32a-smpA was transformed into the competent expression host E.coliRosetta-gami2 (DE3) by calcium chloride method and plated onto the LB agar which contained $100 \mu \mathrm{g} / \mathrm{mL}$ of ampicillin and $35 \mu \mathrm{g} / \mathrm{mL}$ of chloramphenicol. The recombinant E. coliDE3 was grown in $5 \mathrm{~mL}$ LB broth containing ampicillin $(100 \mu \mathrm{g} / \mathrm{mL})$ and chloramphenicol (35 $\mu \mathrm{g} / \mathrm{mL}$ ) on shaking incubator for overnight at $37^{\circ} \mathrm{C}$. Then, $500 \mu \mathrm{L}$ of culture was inoculated in $50 \mathrm{~mL}$ of $\mathrm{LB}$ broth medium at $37^{\circ} \mathrm{C}$ with agitation at $200 \mathrm{rpm}$. The cells grew until the optical density reached $0.6-0.8$ at $600 \mathrm{~nm}$. Expression of the SmpA protein was induced by the addition of $0.9 \mathrm{~m} \mathrm{M}$ IPTG and incubated for five hours at 250 $\mathrm{rpm} / \mathrm{min}$, in $37^{\circ} \mathrm{C}$. Afterwards, it was harvested by centrifugation and whole cell lysates was analyzed by SDS-PAGE $12 \%$. In this case, E.coliDE3 without pET32a-smpA was used as a control. The E. coli DE3 was also transformed with empty vector PET32a which was induced by IPTG applying as a negative control. The mentioned control confirms that empty vector does not express any proteins with similar molecular weight to our target protein (SmpA). 


\subsection{RNA Extraction}

Total RNA was extracted from $1 \times 10^{7}$ the recombinant E. coli DE3 containing PET32a-smpA induced by IPTG using RNX-Plus reagent (SinaClon, Iran) according to the manufacturer's protocol. The concentration and purity of the genomic DNAs were evaluated by Nanodrop ND-1000 spectrophotometer (Nanodrop Technologies, Wilmington, DE, USA) reading at wave length $230 \mathrm{~nm}, 260 \mathrm{~nm}$ and $280 \mathrm{~nm}$. The RNA was considered pure if the absorbance ratio of 260 $\mathrm{nm} / 280 \mathrm{~nm}$ and $260 \mathrm{~nm} / 230 \mathrm{~nm}$ was around 2.

\subsection{Complementary DNA ( $C D N A)$ Synthesis and RT-PCR}

Complementary DNA (cDNA) was synthesized using a reaction containing $500 \mathrm{ng} / \mu \mathrm{L}$ RNA, $100 \mathrm{mM}$ dNTPs, $10 \mu \mathrm{L}$ 5x RT-PCR buffer, $200 \mathrm{mM}$ oligdT primer and $1 \mathrm{U} / \mu \mathrm{L}$ M-MuLV reverse transcriptase, (Invitrogen, USA) in a total volume $20 \mu \mathrm{L}$. The mixture was incubated at $42^{\circ} \mathrm{C}$ for one hour followed by enzyme inactivation; 15 minutes in $70^{\circ} \mathrm{C}$. The smpA transcript was amplified using the specific primers as mentioned above. The reaction was performed in total volume of $20 \mu \mathrm{L}$ containing $50 \mathrm{mM} \mathrm{MgCl}_{2}, 0.25 \mathrm{mM}$ of each dNTP, 2 pmol/L of each primer, $400 \mathrm{ng} / \mu \mathrm{L}$ cDNA templates and1 U of Taq DNA polymerase (Fermentas, Germany). The final volume was adjusted with nuclease-free water. PCR was optimized in thermocycler and comprised of 5 minutes denaturation at $95^{\circ} \mathrm{C}$ for initial denaturation followed by 25 cycles of denaturation; $94^{\circ} \mathrm{C}$ for 1 minute, annealing; $61^{\circ} \mathrm{C}$ for $1 \mathrm{~min}$, extension; $72^{\circ} \mathrm{C}$ for 45 seconds, final extension; $72^{\circ} \mathrm{C}$ for 2 minutes. A sample without DNA template (NTC) was included in all PCR reactions as negative control. The PCR products were then analyzed on $1 \%$ agarose gel electrophoresis dyed with $2 \%$ ethidium bromide and product bands were visualized under ultraviolet light.

\section{Results}

\subsection{Bacterial Isolates and Antimicrobial Susceptibility Testing}

In total 67 samples from patients aged between 20 days and 75 years, out of them, in $44.78 \%(n=30)$ isolates were positive for A. baumannii. These bacteria were recovered from the wound pus (7 isolates), blood (6 isolates), urine ( 2 isolates) and sputum (15 isolates). Antibiotic susceptibility has been listed in High High resistance was observed among the tested antibiotics, excepted Colistin, Polymyxin $B$ and Minocycline. One-hundred percent of the strains exhibited resistance to antibiotics Cefixime, Cefotaxime, Cefoprazone and Erythromycin. One hundred percent of these isolates at least were resistant to four generation of antibiotics and were denominated as MDR or EDR. Twenty resistance patterns of these mentioned isolates were determined by the same method and the results have been presented in Table 2 .

\subsection{DNA Extraction and Amplification of smpA Gene}

The genomic DNA of A. baumannii was successfully extracted through the amplification of smpA gene. The $417 \mathrm{bp}$ PCR product was harmonized to the expected length (Figure 1).

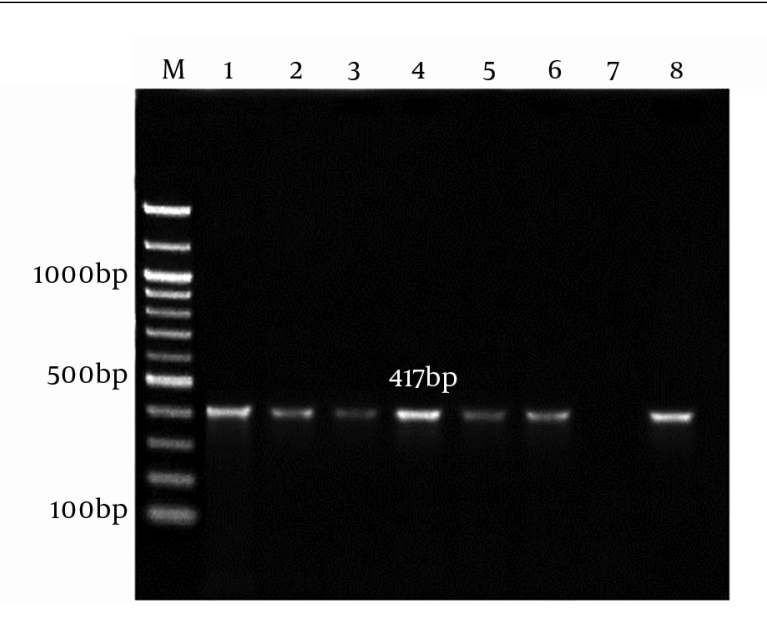

Figure 1. Lane M, 100 bp DNA Marker; Lane 1- 6, an Amplification of Complete smpA Gene from A. baumannii Strain; Lane 7, Negative Control; Lane 8, Positive Control A. baumannii ATCC19606.

\subsection{T/A Cloning}

The appearance of white and blue colonies on LB agar plates was an evidence of successful transformation. Colony PCR and double digestion of pTZ57RT-smpA showed that smpA gene was cloned in pTZ57RT vector successfully (Figure $2 \mathrm{~A}$ and $2 \mathrm{~B}$, respectively).

\subsection{Sub-Cloning smpA and Sequencing}

Analyzing of the double digested and colony PCR from pET32a-smpA showed that the engineered vector contained the gene of interest (Figure 3A and 3B, respectively). The sequencing of $s m p A$ gene showed more than 95\% similarity with smpA published in the NCBI gene bank (Supplementary file 1).

\subsection{Expression of the Recombinant Protein ( $r S m p A)$}

The pET32a-smpA in E.coli DE3 system was induced by IPTG at concentration of $0.9 \mathrm{mmol} / \mathrm{L}$. The results of SDSPAGE demonstrated that the pET32a-smpA efficiently produce rSmpA. The protein band in the range of molecular weight $\sim 15 \mathrm{KDa}$ was found in SDS-PAGE (Figure 4A). Addionally, to examine if the empty vector does not express any proteins with similar molecular weight to our target protein (SmpA), E. coli DE3 was also transformed with empty vector PET32a which was induced by IPTG. Our results showed that the empty vector does not produce any 
Table 2. Antibiotic Resistance Patterns of A. baumannii Clinical Isolates from Patients with Nosocomial Infections, in Different Wards of Imam Ali and Kashani Hospitals

\begin{tabular}{|c|c|c|}
\hline No. & Antibiotic Resistant Patterns & Frequency \\
\hline 1 & AMX,CFX,TIG,CTX,CO,ERY,CC,NAL,CFM,IPM,PB,MIN,OFX,LOM,SMX,CFP,DP & 3 \\
\hline 2 & AMX,CFX,TIG,CTX,ERY,NAL,CFM,IPM,PB,OFX,LOM,SMX,CFP,DP & 1 \\
\hline 3 & AMX,CFX,TIG,CTX,ERY,NAL,CFM,IPM,MIN,LOM,SMX,CFP & 1 \\
\hline 4 & AMX,CFX,TIG,CTX,ERY,NAL,CFM,OFX,LOM,SMX,CFP,DP & 3 \\
\hline 5 & AMX,CFX,TIG,CTX,ERY,NAL,CFM,IPM,OFX,LOM,CFP,DP & 2 \\
\hline 6 & AMX,CFX,TIG,CTX,ERY,CC,NAL,CFM,MIN,OFX,SMX,CFP & 1 \\
\hline 7 & AMX,CFX,TIG,CTX,ERY,NAL,CFM,IPM,PB,OFX,SMX,CFP & 1 \\
\hline 8 & AMX,CFX,TIG,CTX,ERY,NAL,CFM,IPM,OFX,LOM,CFP & 4 \\
\hline 9 & AMX,CFX,CTX,ERY,NAL,CFM,IPM,OFX,LOM,CFP,DP & 1 \\
\hline 10 & AMX,CFX,TIG,CTX,ERY,CFM,IPM,OFX,SMX,CFP,DP & 1 \\
\hline 11 & AMX,CFX,TIG,CTX,ERY,CC,CFM,OFX,SMX,CFP,DP & 3 \\
\hline 12 & AMX,CFX,CTX,ERY,NAL,CFM,OFX,LOM,SMX,CFP & 1 \\
\hline 13 & AMX,CFX,TIG,CTX,ERY,NAL,CFM,IPM,SMX,CFP & 1 \\
\hline 14 & AMX,CTX,ERY,NAL,CFM,IPM,OFX,LOM,CFP,DP & 1 \\
\hline 15 & AMX,CTX,ERY,NAL,CFM,OFX,LOM,SMX,CFP,DP & 1 \\
\hline 16 & AMX,CTX,ERY,CC,NAL,CFM,IPM,MIN,SMX,CFP & 1 \\
\hline 17 & AMX,CFX,CTX,ERY,CFM,OFX,LOM,SMX,CFP & 1 \\
\hline 18 & AMX,CTX,ERY,NAL,CFM,OFX,LOM,SMX,CFP & 1 \\
\hline 19 & AMX,CTX,ERY,NAL,CFM,OFX,LOM,CFP,DP & 1 \\
\hline 20 & AMX,CFX,TIG,CTX,ERY,CFM,OFX,SMX,CFP & 1 \\
\hline Total (\%) & $30(100 \%)$ & \\
\hline
\end{tabular}

Abbreviations: AMX, Amoxicillin; CFM, Cefixime; CFP, Cefoprazone; CFX, Clindamycin, Nalidixic acid, Cefoxitin; CO, Colistin; CTX, Cefotaxime; DP, Imipenem, Doripenem; ERY, Erythromycin; LOM, Levofloxacin; MIN, Minocycline; OFX, Ofloxacin; PB, PolymyxinB; SMX, Sulfamethoxazole; TIG, Tigecycline.

proteins with similar molecular weight to the SampA (Figure 4B).

\subsection{The Expression Level Analysis of smpA gene in Recombinant Bacteria}

The RNA was extracted from the recombinant $E$. coli DE3 containing PET32a-smpA induced by IPTG. The cDNA was then synthesized from the transcripts to amplify in RTPCR using specific primers for smpA. The presence of $417 \mathrm{bp}$ band was surfed by means of electrophoresis (Figure 5).

\section{Discussion}

Acinetobacter baumannii accounts as an important cause of endemic and sporadic nosocomial infections. Recently progressive significant increasing of antibiotic resistance in A. baumannii isolates, created a serious threat to hospitalized patients (6, 8-11). In our study, in around $45 \%$ of isolates A. baumannii was diagnosed, the majority of studied patients were hospitalized in the ICU and most samples were isolated from the sputum cultures (50\%). According to Table 1, among the A. baumannii isolates, except against Colistin, Polymyxin B, Minocycline and Clindamycin, high rates of antibiotic resistance were seen; $100 \%$ were resistance to Cephalosporins and other antibiotics including Amoxicillin and Erythromycin; but the highest resistance to Carbapenms, Quinolones, Sulfonamides and Glycylcyclines were observed. These data are similar to recent researches reported that nosocomial infections caused by the Acinetobacter species are progressively becoming resistant to a broad spectrum of antibiotics $(2,8)$. In studies by Japoni-Nejad and Vakiliin on Iranians resistance to Imipenem and Meropenem, they found higher resistance rates than the observed data in our study $(6,8)$.

Multi drug resistant A. baumannii is a common challenge in treatment of hospital infections in many countries, including America, Italy, Korea, Greece, Belgium and Iraq (9-14).The spread on antibiotic resistance among Ac- 
A

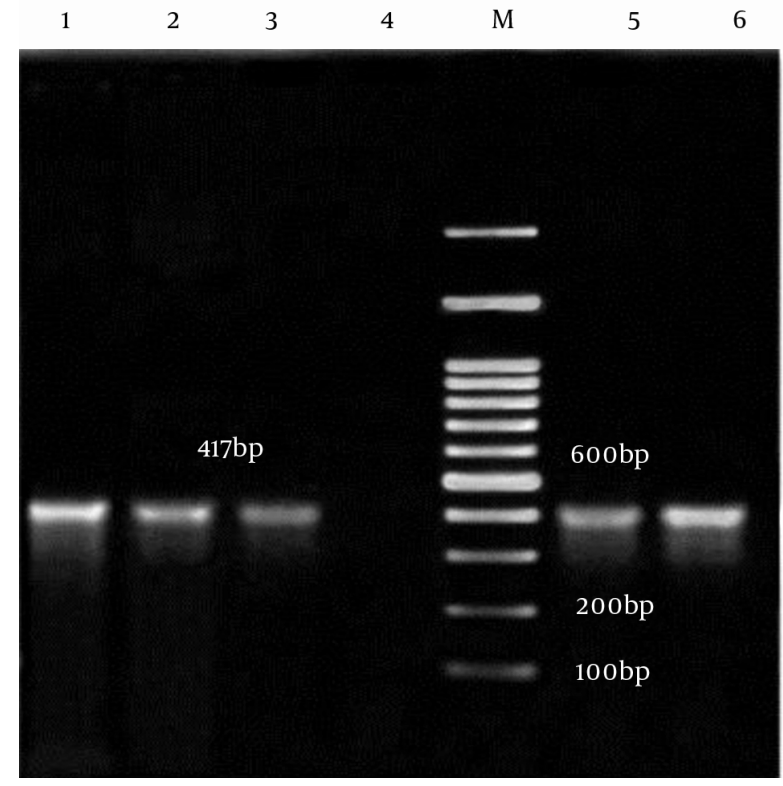

$\mathbf{B}$

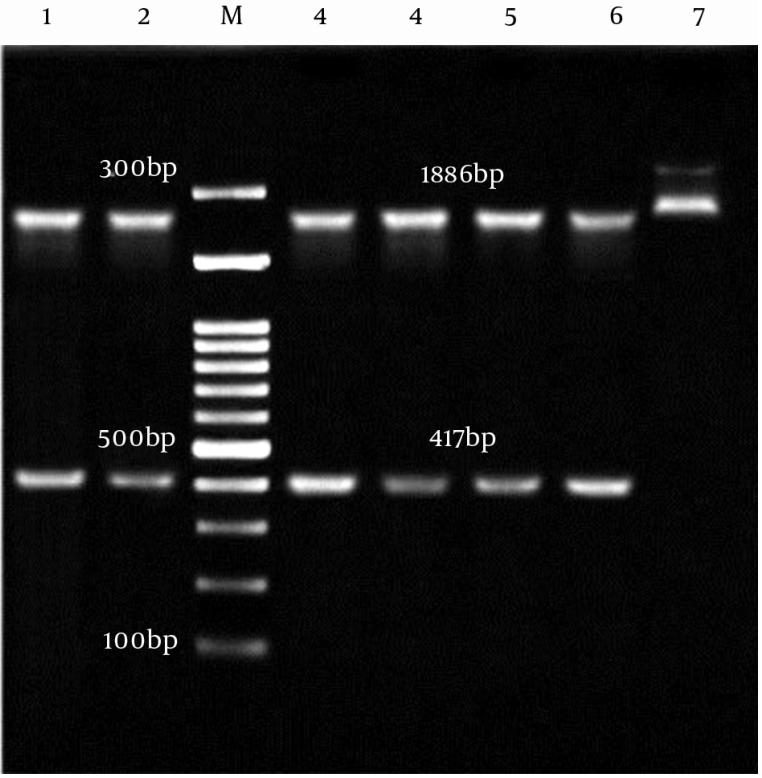

Figure 2. A, Colony PCR of smpA; Lane M:100bp DNA marker; Lane 1-3 and 5, 6: an Amplification of Complete smpA gene (417 bp) from pTZ57RT-smpA; Lane 4: Negative Control; B, Analysis of pTZ57RT-smpA Double Digested; Lane M: 100 bp DNA Marker; Lane 1, 2 and 3 - 6: 2886 bp Segment pTZ57RT and Fragment 417 bp smpA; Lane 7: pTZ57RT-smpA undigested.

A

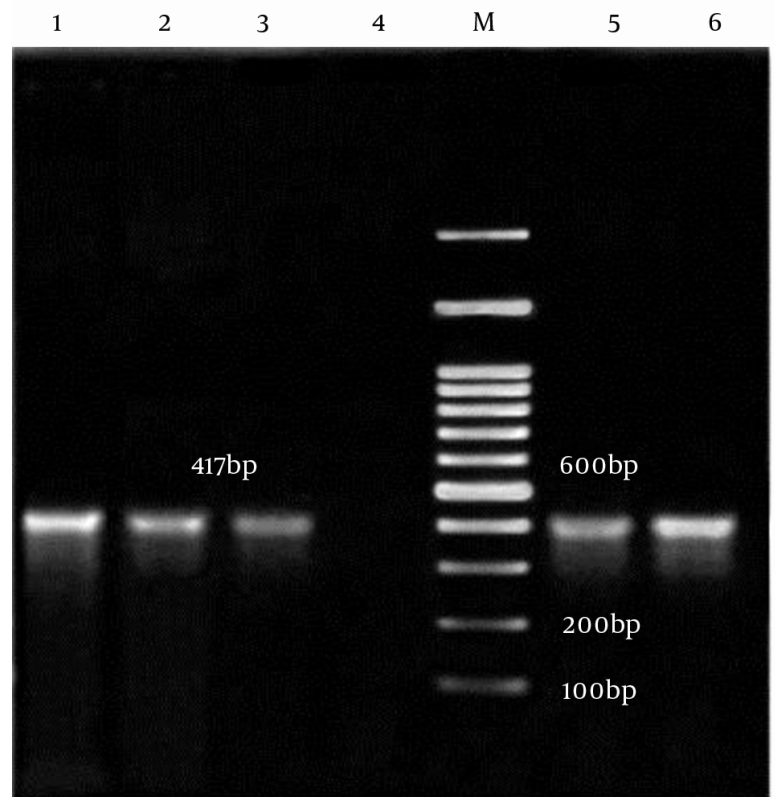

B

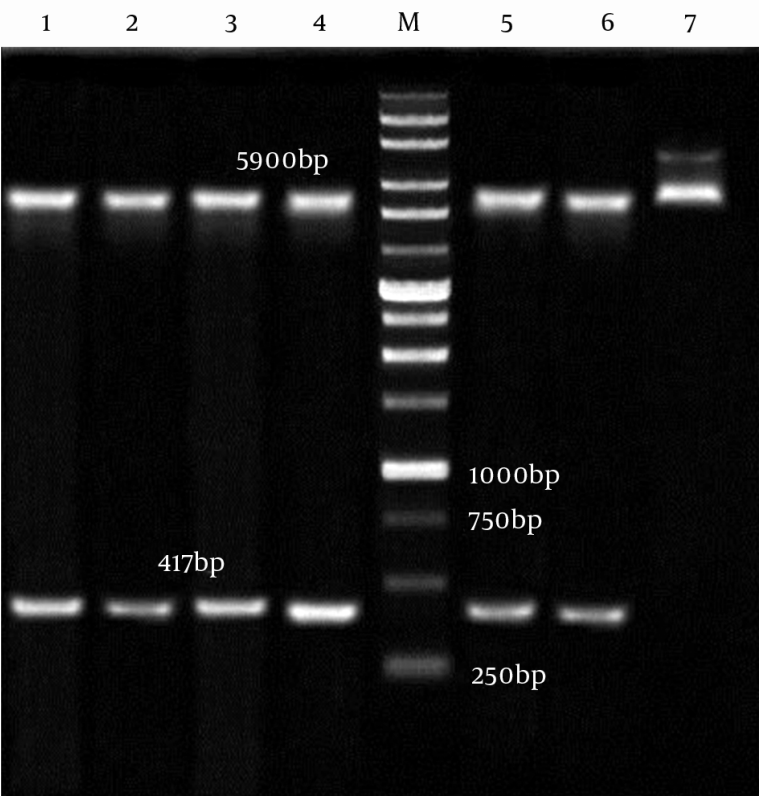

Figure 3. A, Colony PCR of smpA; Lane M, 100 bp DNA Marker; Lane 1-3,5 and 6, an Amplification of Complete smpA Gene (417 bp) from pET32a -smpA; Lane 4, Negative Control; B, pET32a -smpA Double Digested; Lane M:1 Kb DNA Marker; Lane 1- 4,5 and 6, 5900 bp Segment pET32a and Fragment 417 bp smpA; Lane 7, pET32a-smpA Undigested.

intobacter species has emerged as an important challenge

for Iranian infection diseases specialists and medical soci- 
A

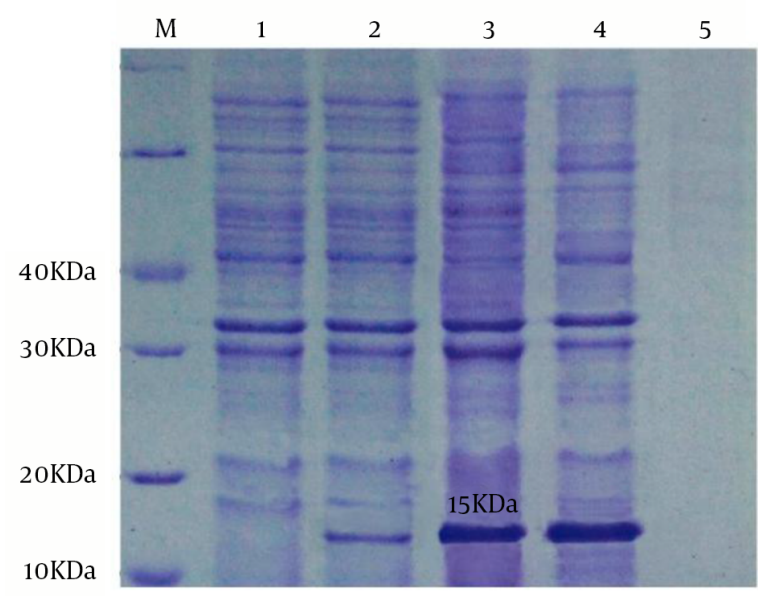

B

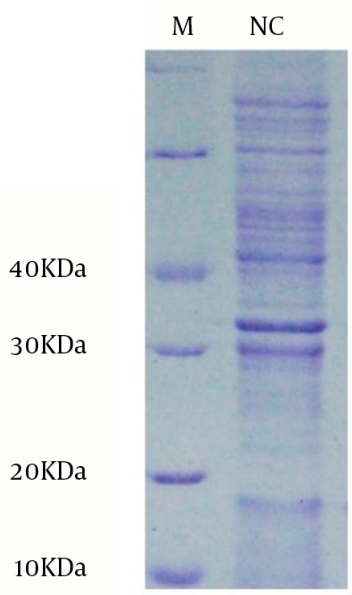

A, lane M, molecular mass marker in $10 \mathrm{kDa}$; lane 1, whole bacterial lysate of the E. coli Rosetta-gami without pET32a-smpA; lane 2, the E. coliDE3 including pET32a-smpA was no induced; lane 3 - 4, the whole bacterial lysate of the E.coliDE3 contained recombinant pET32a-smpA was induced; lane 5, Blank control; B, IPTG-induced E. coli Rosetta-gami with emty pET32a vector.

ety too. A lot of MDR A. baumannii outbreaks have been announced in Iran (1, 2, 6, 20-22). An Iranian surveillance report of antibiotic resistance in $2001-2007$ found that 40.6\% of MDR A. baumannii isolates collected from CMC and local hospitals were Ampicillin and Sulfumetoxazole resistant (15). Another study in Tehran showed that 90\% of A. baumannii isolates were resistance to Cephalosporins (1). In 2010, the Iran Surveillance demonstrated that the prevalence of A. baumannii antibiotic susceptibility to Gentamycin, Tobramycin, Kanamycin and Amikacin decreased gradually from $50 \%, 62.5 \%, 50 \%$ and $81.2 \%$ in 2002 to $28.1 \%$, $25 \%, 15.6 \%$ and $25 \%$ in 2007 , respectively.

Soroush reported that susceptibility rates to Cefteriaxon, Cefixime, Ceftizoxime, Cephalotinand Ceftazidime were $43.7 \%, 50 \%, 31.2 \%, 31.2 \%$ and $50 \%$ in 2001 decreased to $9.3 \%, 0 \%, 18.7 \%, 0 \%$, and $0 \%$ in 2007 respectively (15); and A. baumannii Multi-drug and Extreme-drug resistant increased from $40.6 \%$ in 2002 to $95 \%$ in $2014(8,15)$. In addition, the distribution of healthcare-associated infections caused by A. baumannii resistant to Carbapenem in Iran has been significantly increased, and the frequency resistance rate to Carbapenem was increased progressively from $13.6 \%$ in 2008 (23) to the $83 \%$ in 2014 (8).

Our study showed that out of seventeen antibiotics, Colistin, Polymyxin B and Minocycline were suitable antibiotics to be used in infection medication, by considering of their side effects. However, the rest of the studied antibiotics were inefficient. Carbapenems have been reported operative antibiotic with lower resistance rate in some studies in Iran $(20,21)$, but our finding do not confirm this conclusion.

In a recent study in Iran, Imipenem resistance in enteric bacteria isolated from hospital infections have been reported equal to $33 \%$, which is dissimilar with our results (22). We found that Meropenem and Imipenem were inefficient combat A. baumanni isolates by disc diffusion method. The findings of several studies have demonstrated that Colistin medication in patients with MDR A. baumanii caused an admirable clinical effect and little mortality $(8,24)$.Therefore, this increased usage perchance lead to Colistin resistance and choice of suitable antibiotic therapy is necessary. Different studies reported that Colistin resistant $A$. baumannii have increased gradually all over the world, including Korea (from 9.1\% in 2002 to $30.6 \%$ in 2007) $(25,26)$, Spain (from 19.1\% in 2005 to $40.7 \%$ in 2009) (27, 28) and lower frequency of resistance were observed in USA and South America (2.1\% and 7.1\%, respectively) (26).

In the current study, a total 20 phenotypic patterns were observed, three strain resistance to 17 antibiotic and $100 \%$ isolates resistance to at least 5 antibiotics. Different patterns have been explained in earlier studies $(6,28)$ and evidently variable of resistance patterns in different populations might be due to some factors including: hospitalized patients staying, doctors, prescribing clothing, patients visiting, and expenditure policies (26-29), as well as differences in climatic condition and methods of sample collection. Increase of MDR and PDR organisms has led to anxiety in the medical society, hence, there is an ur- 
Figure 5. Expression Analysis of smpA Transcript Using RT-PCR

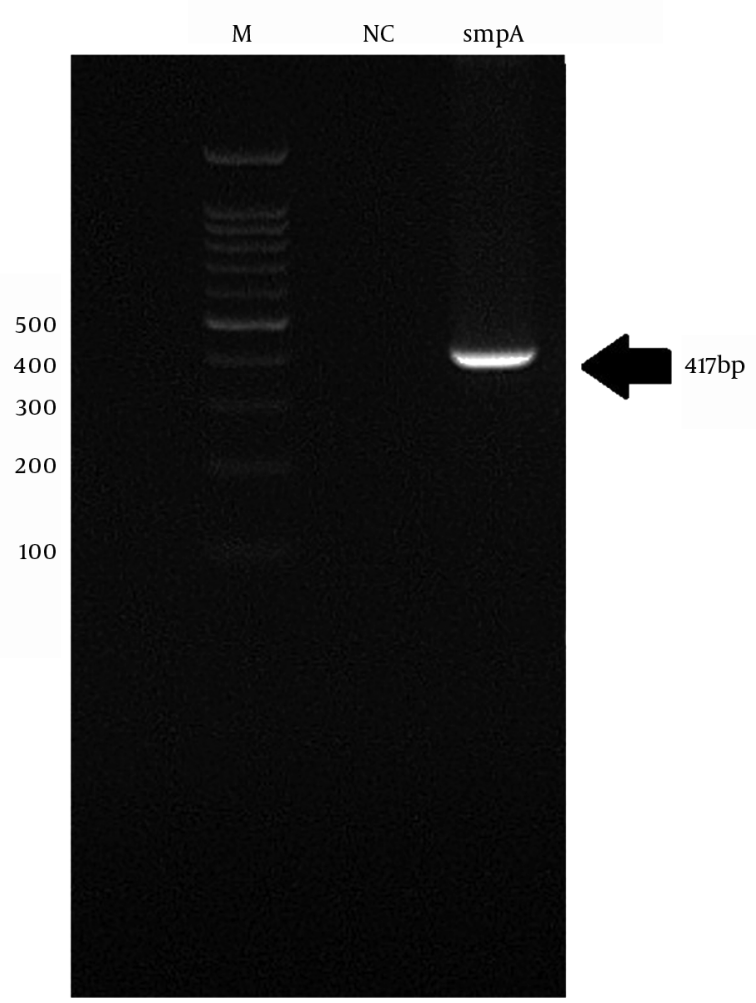

The presence of $417 \mathrm{bp}$ band confirmed that the vector successfully express the target gene in recombinant bacteria. Size Marker: M, Negative control: NC and smpA: amplified smpA.

gent need to novel strategies to combat this MDR and PDR pathogen. Therefore, based on the urgent need for prevention of A. baumannii infections, we generated a recombinant pET-32a/smpA expression vector for produce $\mathrm{rSmpA}$ as a recombinant vaccine candidate. In order to achieve this goal, at first, smpA gene of A. baumannii was amplified and were cloned successfully in PTZ57RT vector and then subcloned in linearized pET32a expression vector and successfully pET-32a/smpA construct is generated. Based on our knowledge, this is the first report on the isolation, cloning and prokaryotic expression antigenic smpA gene detected the clinical strains of A. baumanni in the world.

Outer membrane proteins have critical functions in bacterial survival, host invasion, virulence, immune evasion, cell adhesion and cell death. Outer membrane proteins are mostly immunogenic and appearance on the cell surface, and seem to be potential antigen candidates. Several previous studies demonstrated that some protein components of A. baumannii outer membrane proteins and outer membrane vesicles were exceedingly immuno- genic (3-5), so they were considered as potential antigen candidates for further recognition. Based on these findings, using information of reported clinical A. baumannii isolates, bioinformatics analyses on sequence conservation and possible classification of candidate proteins, the extremely conserved, secretory proteins or predicted membrane were chosen preferentially.

The SmpA is a candidate protein confirmed by bioinformatics estimation of $A$. baumannii proteome (30). It is a putative outer membrane assembly protein. Although its accurate role in virulence is unidentified, presence of SmpA in infective clinical isolates and in the outer membrane vesicles of infesting clinical strains makes it as a critical antigen. Bioinformatics analysis demonstrated its localization in outer membrane, no transmembrane helices, high adhesion probability, conservation between the different strains of A. baumannii $(5,18,19)$. SmpA dissimilarity with mouse and human proteome indicated that the risk for SmpA-stimulated antibodies to cross-recognize human proteins is theoretically imperceptible, so this property presenting it as a highly potential candidate vaccine. Therefore produced SmpA in the present study is a potent antigen candidate for developing an effective vaccine for prevention of A. baumannii infections.

\section{Conclusions}

Result of this study indicated $100 \%$ of the investigated Acinetobacter isolates were tremendously resistant to Cephalosporins and high antibiotic resistance rates to other antibiotics such as Quinolones, Sulfonamides, Glycylcyclines and Carbapenms were also seen, that it may be due to unwise and inappropriate use of antibiotics to treat infections. The four most effective antibiotics against Acinetobacter were found to be Colistin, Polymyxin $\mathrm{B}$, Minocycline and Clindamycin. Also, the recombinant form of the SmpA protein showed high expression in E. coli, so we suggested that this rSmpA protein may be suitable as a vaccine candidate. However, for evaluation such potential, further studies such as evaluation in animal models and Human clinical trials will be needed.

\section{Acknowledgments}

This study is part of $\mathrm{PhD}$ thesis which was granted by Fars Islamic Azad University. The Authors are thankful from Farzam Latifi and all the colleagues in biotechnology research center, Islamic Azad University Shahrekord for their gorgeous assistant in this project. 


\section{Footnotes}

Authors' Contribution: Study design: Dr. Abbas Doosti and Dr. Mohammad Kargar; literature review: Hossein Ansari and Mojtaba Jaafarinia; data Analysis: Hossein Ansari; manuscript preparation: Hossein Ansari, Dr. Abbas Doosti, Dr. Mohammad Kargar and Dr. Mahdi Bijanzadeh.

Financial Disclosure: None.

Statement of Human and Animal Right: None.

Statement of Informed Consent: None.

Funding/Support: This study was supported by Hossein Ansari.

Conflict of Interest: The authors declare no conflict of interest

\section{References}

1. Vahdani P, Yaghoubi T, Aminzadeh Z. Hospital acquired antibioticresistant acinetobacter baumannii infections in a 400-bed hospital in Tehran, Iran. Int J Prev Med. 2011;2(3):127-30. [PubMed: 21811653].

2. Mohajeri P, Farahani A, Feizabadi MM, Ketabi H, Abiri R, Najafi F. Antimicrobial susceptibility profiling and genomic diversity of Acinetobacter baumannii isolates: A study in western Iran. Iran J Microbiol. 2013;5(3):195-202. [PubMed: 24475323].

3. Alzubaidi ANA, Alkozai ZMF. Immunogenic properties of outer membrane protein of Acinetobacter baumannii that loaded on chitosan nanoparticles. Am J BioMed. 2015;3(2):59-74.

4. Singh R, Garg N, Capalash N, Kumar R, Kumar M, Sharma P. In silico analysis of Acinetobacter baumannii outer membrane protein BamA as a potential immunogen. Int J Pure Appl Sci Technol. 2014;21(2):32-9.

5. Al-Warid RJM, Al-Thahab AAL. Cellular immune response to outer membrane proteins isolated. Int. J. Res. Appl. Natural Social. Sci. 2014;2(1):91-6.

6. Japoni-Nejad A, Sofian M, van Belkum A, Ghaznavi-Rad E. Nosocomial outbreak of extensively and pan drug-resistant Acinetobacter baumannii in tertiary hospital in central part of Iran. Jundishapur J Microbiol. 2013;6(8):e9892. doi:10.5812/jjm.9892.

7. Alcantar-Curiel MD, Garcia-Torres LF, Gonzalez-Chavez MI, MorfinOtero R, Gayosso-Vazquez C, Jarillo-Quijada MD, et al. Molecular mechanisms associated with nosocomial carbapenem-resistant Acinetobacter baumannii in Mexico. Arch Med Res. 2014;45(7):553-60. doi 10.1016/j.arcmed.2014.10.006. [PubMed: 25450581].

8. Vakili B, Fazeli H, Shoaei P, Yaran M, Ataei B, Khorvash F, et al. Detection of colistin sensitivity in clinical isolates of Acinetobacter baumannii in Iran. J Res Med Sci. 2014;19(Suppl 1):S67-70. [PubMed: 25002899].

9. Shelburne S3, Singh KV, White AJ, Byrne L, Carmer A, Austin C, et al. Sequential outbreaks of infections by distinct Acinetobacter baumannii strains in a public teaching hospital in Houston, Texas. J Clin Microbiol. 2008;46(1):198-205. doi: 10.1128/JCM.01459-07. [PubMed: 18003801].

10. Zarrilli R, Casillo R, Di Popolo A, Tripodi MF, Bagattini M, Cuccurullo $S$, et al. Molecular epidemiology of a clonal outbreak of multidrug-resistant Acinetobacter baumannii in a university hospital in Italy. Clin Microbiol Infect. 2007;13(5):481-9. doi: 10.1111/j.14690691.2006.01675.x. [PubMed: 17430339].

11. Jeong SH, Bae IK, Park KO, An YJ, Sohn SG, Jang SJ, et al. Outbreaks of imipenem-resistant Acinetobacter baumannii producing carbapenemases in Korea. J Microbiol. 2006;44(4):423-31. [PubMed: 16953178].

12. Markogiannakis A, Fildisis G, Tsiplakou S, Ikonomidis A, Koutsoukou A, Pournaras $S$, et al. Cross-transmission of multidrug-resistant
Acinetobacter baumannii clonal strains causing episodes of sepsis in a trauma intensive care unit. Infect Control Hosp Epidemiol. 2008;29(5):410-7. doi: 10.1086/533545. [PubMed: 18419362].

13. Bogaerts P, Naas T, Wybo I, Bauraing C, Soetens O, Pierard D, et al. Outbreak of infection by carbapenem-resistant Acinetobacter baumannii producing the carbapenemase OXA-58 in Belgium. JClin Microbiol. 2006;44(11):4189-92. doi: 10.1128/JCM.00796-06. [PubMed: 16957031].

14. Scott P, Deye G, Srinivasan A, Murray C, Moran K, Hulten E, et al. An outbreak of multidrug-resistant Acinetobacter baumannii-calcoaceticus complex infection in the US military health care system associated with military operations in Iraq. Clin Infect Dis. 2007;44(12):1577-84. doi: 10.1086/518170. [PubMed: 17516401].

15. Soroush S, Haghi-Ashtiani MT, Taheri-Kalani M, Emaneini M, Aligholi M, Sadeghifard N, et al. Antimicrobial resistance of nosocomial strain of Acinetobacter baumannii in Children's Medical Center of Tehran: a 6-year prospective study. Acta Medica Iranica. 2010;48(3):178-84.

16. Luo D, Ni B, Li P, Shi W, Zhang S, Han Y, et al. Protective immunity elicited by a divalent DNA vaccine encoding both the L7/L12 and Omp16 genes of Brucella abortus in BALB/C mice. Infect Immun. 2006;74(5):2734-41. doi: 10.1128/IAI.74.5.2734-2741.2006. [PubMed: 16622210].

17. Yan J, Mao YF. Construction of a prokaryotic expression system of vacA gene and detection of vacA gene, VacA protein in Helicobacter pylori isolates and ant-VacA antibody in patients' sera. World J Gastroenterol. 2004;10(7):985-90. [PubMed: 15052679].

18. Sklar J. G. , Wu T. , Gronenberg L. S. , Malinverni J. C. , Kahne D. , Silhavy T. J. . Lipoprotein SmpA is a component of the YaeT complex that assembles outer membrane proteins in Escherichia coli. Proc Nat Acad Sci. 2007;104(15):6400-5. doi: 10.1073/pnas.0701579104. [PubMed: 17404237].

19. Sklar JG, Wu T, Gronenberg LS, Malinverni JC, Kahne D, Silhavy TJ. Lipoprotein SmpA is a component of the YaeT complex that assembles outer membrane proteins in Escherichia coli. Proc Natl Acad Sci U S A. 2007;104(15):6400-5. doi: 10.1073/pnas.0701579104. [PubMed: 17404237].

20. Rahbar M, Mehrgan H, Aliakbari NH. Prevalence of antibioticresistant Acinetobacter baumannii in a 1000-bed tertiary care hospital in Tehran, Iran. Indian J Pathol Microbiol. 2010;53(2):290-3. doi: 10.4103/0377-4929.64333. [PubMed: 20551535].

21. Asadollahi K, Alizadeh E, Akbari M, Taherikalani M, Niakan M, Maleki A, et al. The role of bla(OXA-like carbapenemase) and their insertion sequences (ISS) in the induction of resistance against carbapenem antibiotics among Acinetobacter baumannii isolates in Tehran hospitals. Roum Arch Microbiol Immunol. 2011;70(4):153-8. [PubMed: 22568262].

22. Hashemi SH, Esna-Ashari F, Tavakoli S, Mamani M. The prevalence of antibiotic resistance of Enterobacteriaceae strains isolated in community- and hospital-acquired infections in teaching hospitals of Hamadan, west of Iran. J Res Health Sci. 2013;13(1):75-80. [PubMed: 23772019].

23. Japoni S, Japoni A, Farshad S, Ali AA, Jamalidoust M. Association between existence of integrons and multi-drug resistance in Acinetobacter isolated from patients in southern Iran. Pol J Microbiol. 2011;60(2):163-8. [PubMed: 21905635].

24. Ducel G, Fabry J, Nicolle L. Prevention of hospital-acquired infections: a practical guide. ; 2002.

25. Ko KS, Suh JY, Kwon KT, Jung SI, Park KH, Kang CI, et al. High rates of resistance to colistin and polymyxin B in subgroups of Acinetobacter baumannii isolates from Korea. J Antimicrob Chemother. 2007;60(5):1163-7. doi: 10.1093/jac/dkm305. [PubMed: 17761499].

26. Cai Y, Chai D, Wang R, Liang B, Bai N. Colistin resistance of Acinetobacter baumannii: clinical reports, mechanisms and antimicrobial strategies. J Antimicrob Chemother. 2012;67(7):1607-15. doi: 10.1093/jac/dks084. [PubMed: 22441575]. 
27. Arroyo LA, Mateos I, Gonzalez V, Aznar J. In vitro activities of tigecycline, minocycline, and colistin-tigecycline combination against multi-and pandrug-resistant clinical isolates of Acinetobacter baumannii group. Antimicrob Agents Chemother. 2009;53(3):1295-6. doi: 10.1128/AAC.01097-08.

28. Karmostaj A, Najar Peerayeh S, Hatef Salmanian A. Emergence of Tigecycline Resistant Acinetobacter baumannii from an Intensive Care Unit(ICU) in Tehran.JundishapurJMicrobiol. 2013 doi: 10.5812/jjm.4710.

29. Arroyo LA, Garcia-Curiel A, Pachon-Ibanez ME, Llanos AC, Ruiz M, Pa- chon J, et al. Reliability of the E-test method for detection of colistin resistance in clinical isolates of Acinetobacter baumannii.JClin Microbiol. 2005;43(2):903-5. doi: 10.1128/JCM.43.2.903-905.2005. [PubMed: 15695701].

30. Moriel DG, Beatson SA, Wurpel DJ, Lipman J, Nimmo GR, Paterson DL, et al. Identification of novel vaccine candidates against multidrug resistant Acinetobacter baumannii. PLoS One. 2013;8(10):e77631. doi: 10.1371/journal.pone.0077631. [PubMed: 24116234]. 